sternotomy with left thoracotomy 19 days after TEVAR. The patient has survived for 10 months since the operation without any adverse events.

\section{DISCUSSION}

Recently, TEVAR has been applied to treat mycotic aortic aneurysms to minimize the invasiveness of open surgery, although placement of an endovascular graft in an infected environment remains controversial. ${ }^{4}$ When the infection persists after TEVAR, it is likely to lead to a subsequent irremediable disaster. In such conditions, adjunct procedures are necessary to eliminate the source of infection, and percutaneous drainage of an infected aneurysmal sac is suggested as one of several potentially useful interventions.

For high-risk patients, we propose the temporary use of TEVAR, ${ }^{5}$ with or without the irrigation of the infected aneurysmal sac, before open surgery, thus stabilizing the infection and allowing for a safer open reconstruction. In the case of patient 2, we administered daily irrigation with gentian violet solution through a drainage tube to help sterilize the infected bed. The shielding offered by TEVAR allowed us to insert a drainage tube safely into the infected aneurysmal cavity; this method is certainly novel.

Gentian violet, a triphenylmethane dye, has a bactericidal effect against Candida species, streptococci, and staphylococci (including methicillin-resistant $S$ aureus). It is also moderately effective against gram-negative bacteria. Gentian violet has been used to treat skin infections, and its application in the setting of prosthetic graft infection was recently reported.

The use of bridging TEVAR allowed us to effect an improvement in the patient's condition and to perform the necessary drainage and irrigation of the aneurysmal sac before open surgery. We therefore believe that a combination of bridging TEVAR and aneurysmal sac irrigation is a superior alternative strategy for treating critically ill patients with mycotic thoracic aortic aneurysms relative to the use of either single-stage open surgery or TEVAR alone.

\section{References}

1. Hsu RB, Lin FY. Surgery for infected aneurysm of the aortic arch. J Thorac Cardiovasc Surg. 2007;134:1157-62.

2. Uchida N, Katayama A, Tamura K, Miwa S, Masatsugu K, Sueda T. In situ replacement for mycotic aneurysms on the thoracic and abdominal aorta using rifampicin-bonded grafting and omental pedicle grafting. Ann Thorac Surg. 2012;93:438-42.

3. Igari K, Jibiki M, Kudo T, Sugano N, Inoue Y. Drainage surgery followed by postoperative irrigation with gentian violet for prosthetic graft infection caused by methicillin-resistant Staphylococcus aureus. Eur J Vasc Endovasc Surg. 2011; 41:278-80.

4. Kan CD, Lee HL, Yang YJ. Outcome after endovascular stent graft treatment for mycotic aortic aneurysm: a systematic review. J Vasc Surg. 2007;46: 906-12.

5. Tamura K, Yoshitaka H, Totsugawa T, Tsushima Y, Chikazawa G, Ohno T, et al. Bridge use of endovascular repair and delayed open operation for infected aneurysm of aortic arch. Ann Thorac Surg. 2013;96:1471-3.

\title{
Minimally invasive triple valve surgery through a right minithoracotomy
}

\author{
Antonio Lio, MD, ${ }^{\mathrm{a}}$ Michele Murzi, MD, ${ }^{\mathrm{a}}$ Marco Solinas, MD, ${ }^{\mathrm{a}}$ and Mattia Glauber, MD, ${ }^{\mathrm{b}}$ Massa and \\ Milan, Italy
}

Triple valve surgery (TVS) is still a challenge for surgeons owing to the prolonged cardiopulmonary bypass and myocardial ischemic times, with a reported operative

\footnotetext{
From the Department of Adult Cardiac Surgery, ${ }^{\mathrm{a}}$ Fondazione Toscana G. Monasterio, Massa, Italy; and Humanitas Clinical and Research Center, ${ }^{\mathrm{b}}$ Milan, Italy.

Disclosures: Mattia Glauber is the inventor of the CardioVision Glauber aortic clamp. All other authors have nothing to disclose with regard to commercial support.

Received for publication May 16, 2014; revisions received June 16, 2014; accepted for publication June 29, 2014; available ahead of print Aug 21, 2014.

Address for reprints: Antonio Lio, MD, Department of Adult Cardiac Surgery,

Fondazione Toscana G. Monasterio, Via Aurelia Sud, Massa 54100, Italy

(E-mail: antoniolio@ hotmail.it).

J Thorac Cardiovasc Surg 2014;148:2424-7

$0022-5223 / \$ 36.00$

Copyright (c) 2014 by The American Association for Thoracic Surgery

http://dx.doi.org/10.1016/j.jtcvs.2014.06.094
}

mortality of $2.5 \%$ to $25 \% .{ }^{1}$ Furthermore, patients undergoing TVS usually have late stage disease, making them vulnerable during surgery. Few data are available of the treatment of TVS with a minimally invasive approach, although the benefits of minimally invasive cardiac surgery have been well recognized. ${ }^{2}$ We describe our experience with 5 patients who underwent TVS through a right minithoracotomy, with the aim of demonstrating the technical feasibility of this type of surgery.

\section{CLINICAL SUMMARY}

From September 2008 to November 2012, 5 patients were scheduled for TVS through a right minithoracotomy at our institution. The 5 patients were all women (100\%), 
TABLE 1. Patient characteristics

\begin{tabular}{|c|c|c|c|c|c|c|c|c|c|}
\hline Pt no. & Age (y) & Sex & $\begin{array}{c}\text { Logistic } \\
\text { EuroSCORE }\end{array}$ & $\begin{array}{c}\text { Surgery } \\
\text { year }\end{array}$ & $\begin{array}{c}\text { CPB time } \\
(\mathrm{min})\end{array}$ & $\begin{array}{l}\text { Crossclamp } \\
\text { time (min) }\end{array}$ & $\begin{array}{c}\text { Aortic } \\
\text { procedure }\end{array}$ & $\begin{array}{c}\text { Mitral } \\
\text { procedure }\end{array}$ & $\begin{array}{c}\text { Tricuspid } \\
\text { procedure }\end{array}$ \\
\hline 1 & 71 & $\mathrm{~F}$ & 4.52 & 2008 & 228 & 160 & Replacement & Replacement & Annuloplasty \\
\hline 2 & 75 & $\mathrm{~F}$ & 8.34 & 2008 & 260 & 183 & Replacement & Annuloplasty & Annuloplasty \\
\hline 3 & 53 & $\mathrm{~F}$ & 2.08 & 2009 & 178 & 155 & Replacement & Replacement & Annuloplasty \\
\hline 4 & 53 & $\mathrm{~F}$ & 2.08 & 2011 & 155 & 118 & Replacement & Replacement & Annuloplasty \\
\hline 5 & 64 & $\mathrm{~F}$ & 15.78 & 2012 & 169 & 118 & Replacement & Annuloplasty & Annuloplasty \\
\hline
\end{tabular}

Pt no., Patient number; CPB, cardiopulmonary bypass; F, female; EuroSCORE, European System for Cardiac Operative Risk Evaluation.

with a mean age of $63.2 \pm 10.1$ years (range, 53-75). The mean \pm standard deviation weight was $60.8 \pm 8.7$ $\mathrm{kg}$, and mean height was $159.8 \pm 6.0 \mathrm{~cm}$. The mean logistic EuroSCORE was $6.6 \pm 5.8$ (Table 1).

\section{Surgical Management}

An 8- to $10-\mathrm{cm}$ incision was performed in the third intercostal space, 2 to $4 \mathrm{~cm}$ from the sternal edge. After the minithoracotomy, 2 ports were placed, 1 in the third and 1 in the fifth to seventh intercostal space for video assistance, cardiotomy vent, carbon monoxide insufflation, and pericardial stay sutures. The pericardium was opened 3 to $4 \mathrm{~cm}$ to the phrenic nerve and held by stay sutures. Cardiopulmonary bypass was established at $34^{\circ} \mathrm{C}$ using a cannula in the ascending aorta and a double-stage venous return cannula into the right femoral vein. First, using a Seldinger technique, a double-stage venous return cannula (Sorin Biomedica, Saluggia, Italy) was placed percutaneously into the right femoral vein, under the transesophageal echocardiographic guidance, and advanced into the superior vena cava. Next, arterial inflow was established by central cannulation of the ascending aorta using the EasyFlow cannula (Sorin Biomedica; Figure 1).

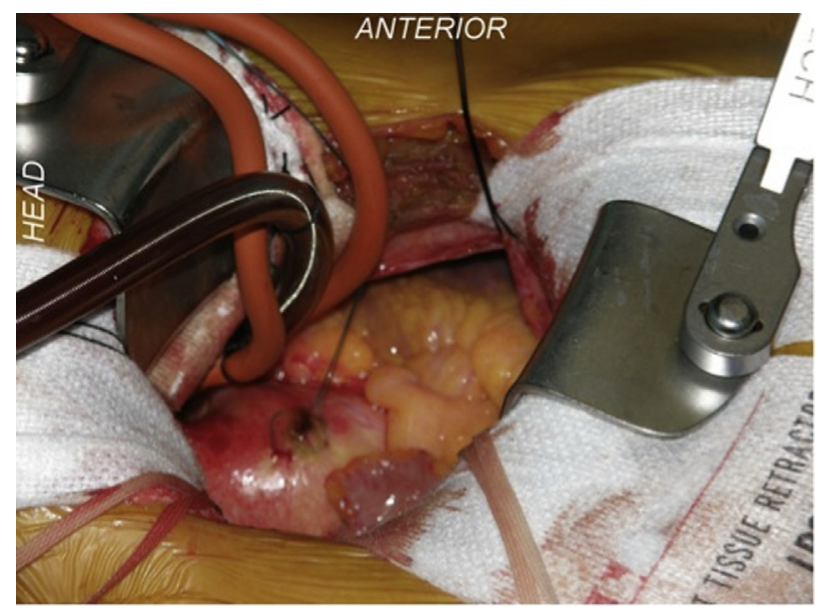

FIGURE 1. Surgeons' view showing right anterolateral minithoracotomy performed in the third intercostal space. The aortic cannula was placed directly into the ascending aorta.
Subsequently, the aorta was directly crossclamped with a Cygnet flexible clamp (Novare Surgical Systems, Inc, Cupertino, Calif) or a Cardiovision Glauber clamp (Sorin Biomedica) designed so the handle is removed after clamp insertion.

Anterograde cardioplegia was delivered as a single dose of crystalloid solution. The aorta was opened transversely, the native valve was inspected and excised, and pledgeted sutures were passed through the annulus. Next, dissection was performed in Sondergaard's groove, and the mitral valve was replaced or repaired. Subsequently, the aortic valve was approached, the prosthesis was lowered, and the sutures were knotted. Finally, the right atriotomy was made, the tricuspid valve was exposed, and repair was subsequently performed with an annuloplasty ring (Figure 2).

\section{Surgical Outcomes}

Of the 5 patients, 2 died in-hospital, 1 of sepsis and 1 of myocardial failure. Postoperatively, 2 patients developed atrial fibrillation, and 1 required placement of a permanent pacemaker for heart block. No cerebral stroke occurred. At a median follow-up of 35 months (range, 0-67), no late death had occurred and the freedom from reoperation was $100 \%$.

\section{DISCUSSION}

TVS through a minithoracotomy is still an uncommon practice. However, a conventional sternotomy approach can significantly alter postoperative recovery, especially in this group of fragile patients.

The minimally invasive thoracotomy approach could have several potential advantages compared with median sternotomy, including a quicker return to normal activity, a shorter mechanical ventilation time, and less blood loss. Moreover, the full sternotomy has been associated with a greater risk of postoperative wound infection and dehiscence than minithoracotomy; eradicating the risk of deep sternal infection is of great value and has been associated with a shorter length of hospital stay.

At our institution, particular attention has been paid to a central aortic cannulation through the thoracotomy. Despite the good results reported for both perfusion techniques, 


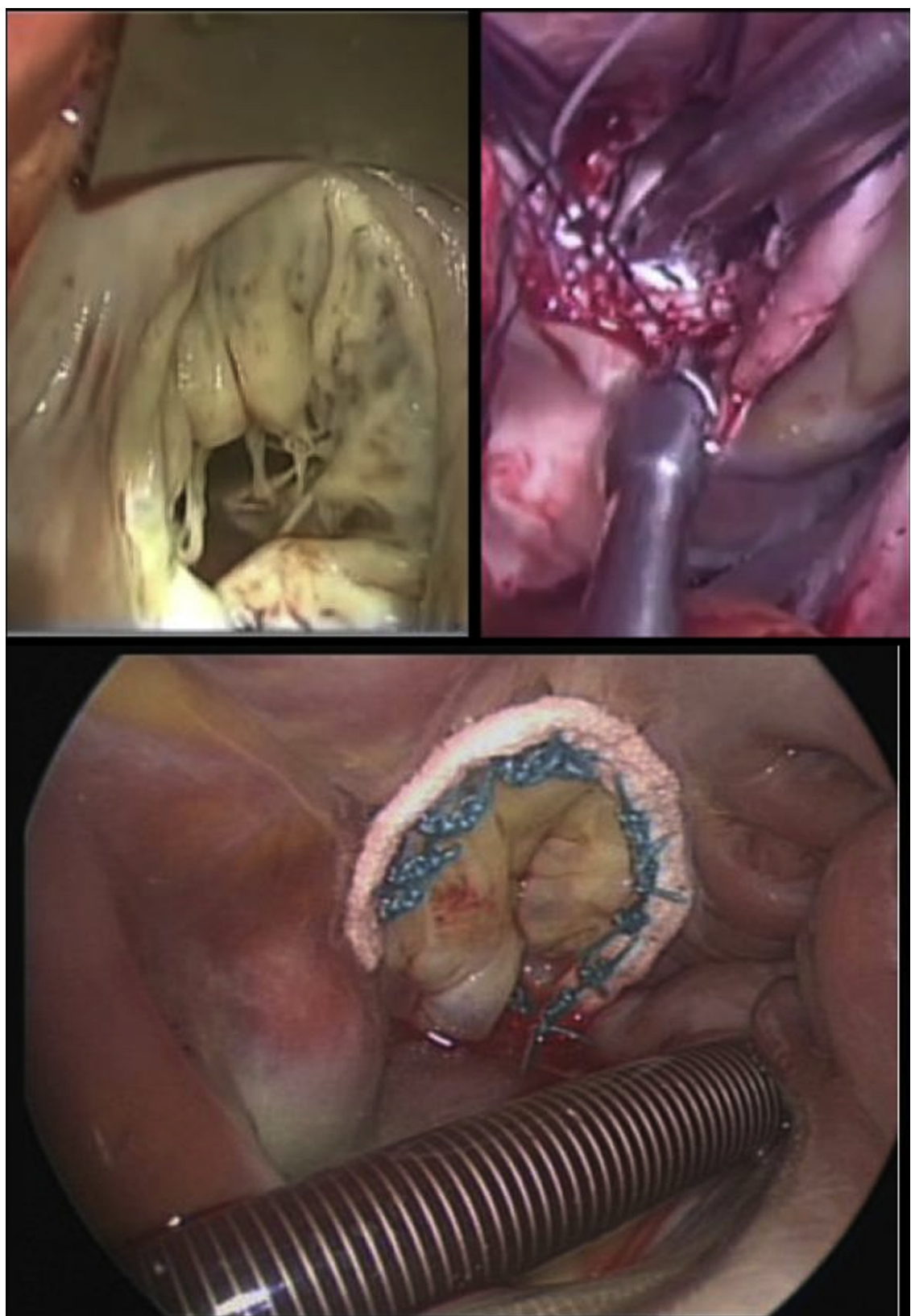

FIGURE 2. Intraoperative view of mitral, aortic, and tricuspid valves. Note that the venous cannula in the right atrium does not prevent visualization of the tricuspid valve.

some retrospective studies have recently raised the suspicion that the retrograde perfusion strategy during minimally invasive cardiac surgery could be associated with an increased risk of neurologic complications compared with antegrade perfusion. ${ }^{3}$ The central aortic cannulation performed in our series allowed the avoidance of these complications.

Moreover, the different choice of valve replacement or repair and the type of eventual valve prosthesis was similar to those used in the median sternotomy operation. Compared with TVS using conventional sternotomy, no significant differences in the cardiopulmonary bypass time (204 \pm 76 minutes vs $202 \pm 56$ minutes in the sternotomy subgroup, $P=.57)$ or crossclamp time (146 $\pm 50 \mathrm{mi}-$ nutes vs $149 \pm 39$ minutes in the sternotomy subgroup, $P=.51)$ were recorded.

\section{CONCLUSIONS}

TVS with a minimally invasive approach and central aortic cannulation could be another treatment option for these high-risk patients. 


\section{References}

1. Alsoufi B, Rao V, Borger MA, Maganti M, Armstrong S, Feindel CM, et al. Shortand long-term results of triple valve surgery in the modern era. Ann Thorac Surg. 2006;81:2172-8.

2. Cohn LH, Adams DH, Couper GS, Bichell DP, Rosborough DM, Sears SP, et al. Minimally invasive cardiac valve surgery improves patient satisfaction while reducing costs of cardiac valve replacement and repair. Ann Surg. 1997; 226:421-8.

3. Gammie JS, Zhao Y, Peterson ED, O'Brien SM, Rankin JS, Griffith BPJ Less-invasive mitral valve operations: trends and outcomes from the Society of Thoracic Surgeons Adult Cardiac Surgery Database. Ann Thorac Surg. 2010;90: 1401-8.

\title{
Novel technique for delayed sternal closure: Soft tissue approximation with substernal bridge
}

\author{
Cha Rajakaruna, MD, ${ }^{a}$ Gladys M. Rodriguez, BS, ${ }^{a}$ Bijoy G. Rajbanshi, MD, \\ Bulat A. Ziganshin, MD, ${ }^{\text {a,b }}$ and John A. Elefteriades, MD, ${ }^{a}$ New Haven, Conn, and Kazan, Russia
}

Delayed sternal closure (DSC) is used when the approximation of the hemisterna after cardiac surgery leads to embarrassment of hemodynamics due to poor cardiac function of a dilated heart or reperfusion myocardial edema after prolonged ischemic time. ${ }^{1,2}$ DSC also can be used when the chest is packed and left open for uncontrolled hemorrhage or when continued access is required for central mechanical circulatory support. DSC often is a measure of last resort when all other maneuvers have failed. DSC is used more frequently in the pediatric population, but it can represent a lifesaving maneuver in the adult population.

Most of the techniques described for DSC involve suturing the skin with a membrane with or without a stent holding the sternal edges apart and then covering the chest with an adhesive airtight dressing. ${ }^{3,4}$

We describe a technique that over many years has been used safely in our practice and offers substantial advantages over other techniques described in the literature. The technique reported has the advantage of complete soft tissue closure, maintaining complete internal mediastinal sterility. In addition, the pericardial bridge protects the heart from the sharp sternal edges. This closure can be permanent if the overall situation so requires. This

\footnotetext{
From the Aortic Institute at Yale-New Haven Hospital, ${ }^{a}$ Yale University School of Medicine, New Haven, Conn; and Department of Surgical Diseases \#2, ${ }^{\text {b }}$ Kazan State Medical University, Kazan, Russia.

Disclosures: John Elefteriades reports consulting fees from Cryolife, Covidien, and Datascope, and equity ownership in Coolspine. The other authors have nothing to disclose with regard to commercial support.

Received for publication July 21, 2014; revisions received Aug 25, 2014; accepted for publication Aug 31, 2014; available ahead of print Oct 1, 2014.

Address for reprints: John A. Elefteriades, MD, Aortic Institute at Yale-New Haven Hospital, Yale University School of Medicine, 789 Howard Ave, Clinic Bldg CB317, New Haven, CT 06510 (E-mail: john.elefteriades@yale.edu).

J Thorac Cardiovasc Surg 2014;148:2427-9

$0022-5223 / \$ 36.00$

Copyright (c) 2014 by The American Association for Thoracic Surgery

http://dx.doi.org/10.1016/j.jtcvs.2014.08.048
}

review was covered by an approved institutional review board protocol.

\section{SURGICAL TECHNIQUE}

We start by placing a pericardial bridge between the nonapproximated sternal halves to prevent heart laceration against the sharp sternal edges (Figure 1). For this purpose, we use a large $(8 \times 14 \mathrm{~cm})$ bovine pericardial patch (Synovis Surgical Innovation, St Paul, Minn), which is sutured underneath each sternal edge with 3 to 5 interrupted mattress sutures (0 Ticron $75 \mathrm{~cm}$ on GS27 needle; Covidien, Mansfield, Mass; 88863190-61). The patch is laid on the heart, and sutures are passed from cardiac side to skin side in a mattress fashion along the length of the pericardial patch. The needles are brought out through the corresponding points of each hemi-sternum and tied on the upper surface of the bone, so that the patch lines the underside of the sternal edges and bridges the gap as shown in Figure 1. Chest tubes are left below the patch.

Next, the muscle and soft tissues overlying the sternum are approximated fully in our usual 3-layer closure ( 0 Vicryl to muscle and rectus fascia, 2-0 Vicryl to the subcutaneous tissues, and 3-0 monofilament suture to skin) reinforced by skin staples (Figure 2). We see little or no hemodynamic embarrassment from approximation of the soft tissues. We can always bring these soft tissues together adequately without lateral mobilization. This soft tissue closure provides 3 complete, watertight layers isolating the mediastinum from the exterior.

Standard wound dressings are applied until the patient is ready for definitive closure when clinically appropriate (usually within a few days of the original operation). Definitive closure is done by reopening, removing the pericardial membrane, approximating the bone with wires, and closing the soft tissues in 3 layers. 